\title{
Efficacy and safety of angiogenesis inhibitors in small-cell lung cancer
}

\author{
Heng Lin ${ }^{1,2, *}$, Lina $\mathrm{Li}^{1, *}$, Shuimei Luo ${ }^{1}$, Sijing Zhou ${ }^{1}$, Ruifen Shen ${ }^{1}$, Haitao Yang ${ }^{1}$, \\ Huijuan Chen ${ }^{1}$, Xianhe Xie ${ }^{1}$ \\ ${ }^{1}$ Department of Chemotherapy, The First Affiliated Hospital, Fujian Medical University, Fuzhou, Fujian, China \\ ${ }^{2}$ Department of Oncology, Fuzhou Pulmonary Hospital, Fuzhou, Fujian, China \\ *These authors have contributed equally to this work \\ Correspondence to: Xianhe Xie, email: xiexianhe@yahoo.com \\ Keywords: angiogenesis inhibitors, chemotherapy, targeted therapy, small-cell lung cancer, meta-analysis \\ Received: July 02,2016 Accepted: November 09,2016 Published: November 25, 2016
}

\section{ABSTRACT}

Objective: The purpose of this study was to investigate the efficacy and safety of angiogenesis inhibitors for small-cell lung cancer (SCLC).

Methods: Totally, 16 controlled trials (1898 cases) involving angiogenesis inhibitors plus chemotherapy (ACT group) versus chemotherapy alone group (CT group) were identified from PubMed, EMBASE, Cochrane Library and Wanfang Data before March 2016.

Results: Compared with CT group, ACT group obtained a significant benefit on objective response rate (ORR) $(R R=1.34 ; 95 \% C I=1.19-1.51 ; P<0.00001)$ and a trend of prolonging progression-free survival (PFS) $(\mathrm{HR}=0.86 ; 95 \% \mathrm{CI}=0.73-$ $1.01 ; P=0.07)$ without improving overall survival $(O S)(H R=1.05 ; 95 \% C I=0.94-$ 1.17; $P=0.36$ ). Remarkably, subgroup analysis showed that the antibodies targeting VEGF significantly prolonged PFS $(H R=0.76 ; 95 \% C I=0.64-0.90 ; P=0.001)$. With regard to toxicity, there was no significant difference in severe adverse events (AEs, Grade $\geq 3$ ) between two groups except that gastrointestinal symptom, hypertension, metabolic disorders, neurology and pain were higher in ACT group.

Conclusion: Compared with chemotherapy alone, antibodies targeting VEGF plus chemotherapy significantly improved ORR and prolonged PFS with an acceptable toxicity profile for patients with SCLC. Therefore, angiogenesis inhibitors, especially antibodies targeting VEGF, combining with chemotherapy may be a potential promising strategy in managing SCLC.

\section{INTRODUCTION}

Small-cell lung cancer (SCLC) accounts for approximately $15 \%$ of all newly diagnosed cases of lung cancer, which is the leading cause of cancer-related death worldwide [1]. About two-thirds of SCLC patients are initially diagnosed at advanced stage, appearing a poor prognosis [2]. For these patients, being unsuitable for surgery or radiotherapy, chemotherapy (CT) (ie, a platinum agent with etoposide or irinotecan) is the main approach [2-5]. Despite the initial high response rate of SCLC to chemotherapy, it can only prolong the median survival time to 7-11 months [6]. Moreover, the first-line therapy has remained essentially unchanged for the past two decades. Therefore, it is urgently needed to seek a multimodality therapy to break the bottleneck of SCLC treatment.

Since preclinical studies demonstrated that angiogenesis played a crucial role in tumor growth [7], it is reasonable to make an attempt to combine angiogenesis inhibitors with chemotherapy. Large randomized controlled trials (RCT) on non-small-cell lung cancer showed the superiority of antiangiogenic agents plus chemotherapy over chemotherapy alone in terms of objective response rate (ORR), overall survival (OS) and progression-free survival (PFS) [8-10]. As for SCLC, some single-arm trials showed favorable efficacy and safety of angiogenesis inhibitors plus chemotherapy [11- 
13] while other trials failed to confirm that [14, 15]. Thus, the role of angiogenesis inhibitors plus chemotherapy in managing SCLC remains controversial.

Thereby, we performed a meta-analysis to investigate the efficacy and safety of angiogenesis inhibitors plus chemotherapy versus chemotherapy alone.

\section{RESULTS}

\section{Study selection and characteristics}

Totally, 1231 articles were screened after searching the relevant databases. By verifying related terms of the study titles and abstracts, 1102 irrelevant articles were removed. Additionally, another 113 unfit designed articles were excluded after scrutinizing full text. Eventually, 16 clinical control trials [16-31] were included. A flowchart depicting inclusion was shown in Figure 1.

There were 1898 patients in the sixteen selected controlled trials, including 956 patients with angiogenesis inhibitors plus chemotherapy and 942 patients with chemotherapy alone. One of these trials involved in zivaflibercept plus CT versus CT [16]; two bevacizumab plus CT versus CT $[17,18]$; six rh-Endostatin plus CT versus CT [19-24]; six thalidomide plus CT versus CT [25-30]; one vandetanib plus CT versus CT [31]. The populations were comparable with respect to demographics, clinical parameters, stage at initial diagnosis in different clinical settings. These results were summarized in Table 1. Among these 16 trials, two were phase III clinical trials $[29,30]$; one phase II- III trial [18]; four phase II trials [16, $17,19,31]$ while nine studies did not mention a trial phase [20-28]. Outcomes included ORR, OS, PFS and severe adverse events (AEs, Grade $\geq 3$ ).

Data for all characteristics were summarized in Table 2. Gender, ECOG PS (Eastern Cooperative Oncology Group performance status) and stage were available for 14, 6, 12 of the 16 trials, respectively. The number of withdrawn patients was approximately the same in each trial.

The information about the types of agents, dosage, duration and sequence administrated in different trials was summarized in Table 3.

\section{Methodological quality}

In accordance with the recommendations of the Cochrane Handbook for Systematic Reviews, we assessed the eligible trials using the seven aspects mentioned above. Among these 16 recruited trials, all referred to the use of random allocation, and one [27] of them discussed the methods, four [17, 29-31] performed or reported their

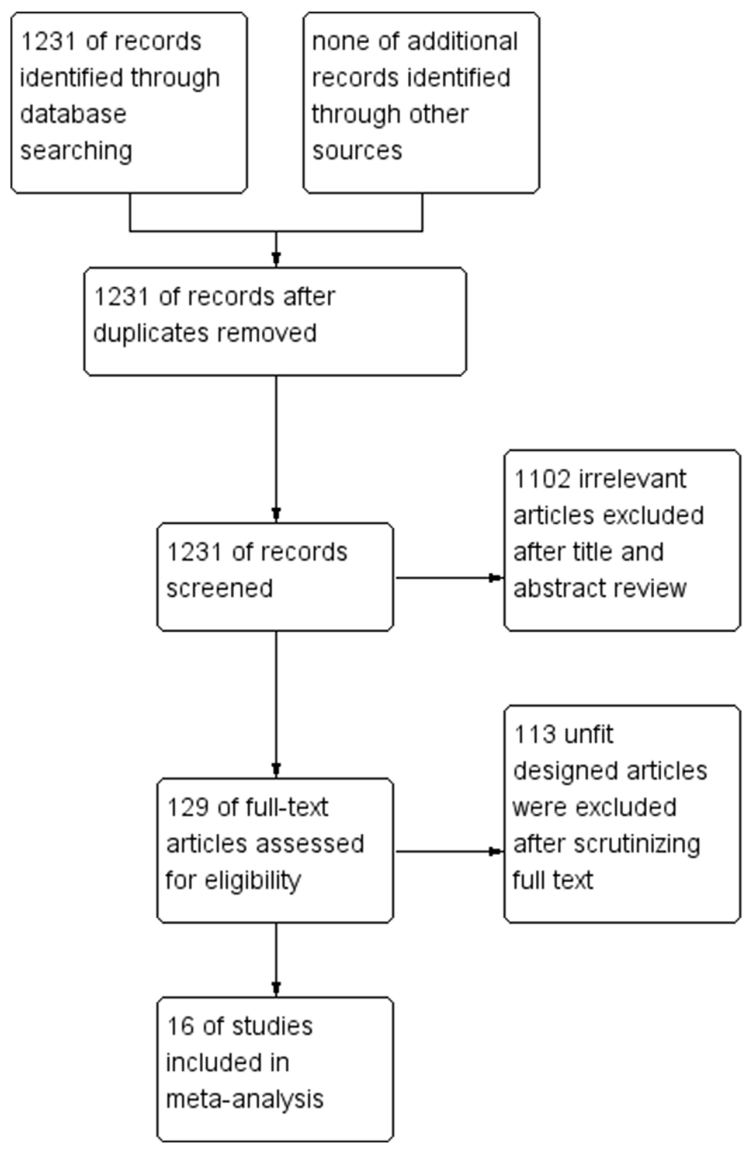

Figure 1: A flow chart on selection included trials in the Meta-analysis. 
Table 1: Baseline characteristic of trials included for analysis

\begin{tabular}{|c|c|c|c|c|c|c|c|c|c|c|c|c|c|c|}
\hline \multirow[t]{2}{*}{ StudyID } & \multirow[t]{2}{*}{ Country } & \multirow{2}{*}{$\begin{array}{c}\text { Trial } \\
\text { phase }\end{array}$} & \multirow[t]{2}{*}{ Line } & \multirow[t]{2}{*}{$\mathbf{N}(\mathrm{A} / \mathrm{C})$} & \multirow{2}{*}{$\begin{array}{c}\operatorname{Ages}(\mathbf{A} / \mathrm{C} \\
\text { Years) }\end{array}$} & \multirow{2}{*}{$\begin{array}{c}\text { Male } \\
(\mathrm{A} / \mathrm{C}, \%)\end{array}$} & \multirow{2}{*}{$\begin{array}{c}P S \leq 2 \\
(\mathrm{~A} / \mathrm{C}, \%)\end{array}$} & \multirow{2}{*}{$\begin{array}{c}\text { Extensive } \\
(\mathrm{A} / \mathrm{C}, \%)\end{array}$} & \multicolumn{2}{|c|}{ Interventions } & \multicolumn{4}{|c|}{ Outcomes } \\
\hline & & & & & & & & & ACT group & CT group & ORR & OS & PFS & $\begin{array}{c}\text { AEs } \\
(\text { grade } \geq 3)\end{array}$ \\
\hline $\begin{array}{l}\text { Allen et } \\
\text { al.2014 }\end{array}$ & America & II & 2 & $97 / 92$ & $62.0 / 62.0$ & $\begin{array}{l}44.33 / \\
51.09\end{array}$ & $\begin{array}{l}100.00 / \\
100.00\end{array}$ & $\begin{array}{l}68.04 / \\
70.65\end{array}$ & $\begin{array}{c}\text { Ziv- } \\
\text { aflibercept+topotecan }\end{array}$ & topotecan & $\mathrm{Y}$ & $\mathrm{Y}$ & $\mathrm{Y}$ & $\mathrm{Y}$ \\
\hline $\begin{array}{l}\text { Spigel et } \\
\text { al.2011 }\end{array}$ & America & II & 1 & $52 / 50$ & $60 / 64$ & $\begin{array}{c}50.00 / \\
60.00\end{array}$ & $\begin{array}{c}100.00 / \\
100.00\end{array}$ & $\begin{array}{c}100.00 / \\
100.00\end{array}$ & Bevacizumab + PE/EC & placebo $+\mathrm{PE} / \mathrm{EC}$ & $\mathrm{Y}$ & $\mathrm{Y}$ & $\mathrm{Y}$ & $\mathrm{Y}$ \\
\hline $\begin{array}{l}\text { Pujol et } \\
\text { al.2015 }\end{array}$ & France & II-III & 1 & $37 / 37$ & $61.2 / 60.1$ & $\begin{array}{l}67.57 / \\
70.27\end{array}$ & $\begin{array}{l}97.30 / \\
100.00\end{array}$ & $\begin{array}{l}100.00 / \\
100.00\end{array}$ & $\begin{array}{l}\text { Bevacizumab+ } \\
\text { PCDE/PE }\end{array}$ & $\mathrm{PCDE} / \mathrm{PE}$ & $\mathrm{N}$ & $\mathrm{Y}$ & $\mathrm{Y}$ & $\mathrm{Y}$ \\
\hline $\begin{array}{l}\text { Lu et } \\
\text { al.2015 }\end{array}$ & China & II & 1 & $69 / 69$ & $57.7 / 58.2$ & $\begin{array}{l}81.16 / \\
82.61\end{array}$ & $\begin{array}{c}100.00 / \\
100.00\end{array}$ & $\begin{array}{c}100.00 / \\
100.00\end{array}$ & rh-Endostatin + EC & $\mathrm{EC}$ & $\mathrm{Y}$ & $\mathrm{Y}$ & $\mathrm{Y}$ & $\mathrm{Y}$ \\
\hline $\begin{array}{l}\text { Luo et } \\
\text { al.2013 }\end{array}$ & China & $\mathrm{N}$ & $\mathrm{N}$ & $19 / 24$ & $56 / 57$ & $\begin{array}{l}78.95 / \\
79.17\end{array}$ & $\mathrm{~N}$ & $\mathrm{~N}$ & rh-Endostatin + EC & $\mathrm{EC}$ & $\mathrm{Y}$ & $\mathrm{N}$ & $\mathrm{N}$ & $\mathrm{Y}$ \\
\hline $\begin{array}{l}\text { Dai et } \\
\text { al.2012 }\end{array}$ & China & $\mathrm{N}$ & $\mathrm{N}$ & $50 / 50$ & $\mathrm{~N}$ & $\mathrm{~N}$ & $\begin{array}{c}100.00 / \\
100.00\end{array}$ & $\mathrm{~N}$ & rh-Endostatin + PE & $\mathrm{PE}$ & $\mathrm{Y}$ & $\mathrm{N}$ & $\mathrm{N}$ & $\mathrm{Y}$ \\
\hline $\begin{array}{l}\text { Li et } \\
\text { al.2010 }\end{array}$ & China & $\mathrm{N}$ & $\mathrm{N}$ & $24 / 24$ & $59 / 56.5$ & $\begin{array}{l}62.50 / \\
66.67\end{array}$ & $\begin{array}{c}100.00 / \\
100.00\end{array}$ & $\begin{array}{c}58.33 / \\
54.17\end{array}$ & rh-Endostatin + PE & PE & $\mathrm{Y}$ & $\mathrm{N}$ & $\mathrm{N}$ & $\mathrm{Y}$ \\
\hline $\begin{array}{l}\text { Wang et } \\
\text { al.2011 }\end{array}$ & China & $\mathrm{N}$ & $\mathrm{N}$ & $20 / 20$ & $56 / 57.2$ & $\begin{array}{l}60.00 / \\
65.00\end{array}$ & $\begin{array}{l}100.00 / \\
100.00\end{array}$ & $\begin{array}{c}55.00 / \\
50.00\end{array}$ & rh-Endostatin + PE & PE & $\mathrm{Y}$ & $\mathrm{N}$ & $\mathrm{N}$ & $\mathrm{Y}$ \\
\hline $\begin{array}{l}\text { Hu et } \\
\text { al.2011 }\end{array}$ & China & $\mathrm{N}$ & $\mathrm{N}$ & $45 / 44$ & $56.5 / 57.8$ & $\begin{array}{c}73.33 / \\
79.55\end{array}$ & $\begin{array}{c}100.00 / \\
100.00\end{array}$ & $\begin{array}{c}46.67 / \\
43.18\end{array}$ & rh-Endostatin + PT & $\mathrm{PT}$ & $\mathrm{Y}$ & $\mathrm{N}$ & $\mathrm{N}$ & $\mathrm{N}$ \\
\hline $\begin{array}{l}\text { Liu et } \\
\text { al.2011 }\end{array}$ & China & $\mathrm{N}$ & $\mathrm{N}$ & $11 / 11$ & $52.64 / 55.63$ & $\begin{array}{l}45.45 / \\
54.55\end{array}$ & $\begin{array}{c}100.00 / \\
100.00\end{array}$ & $\begin{array}{l}72.73 / \\
63.64\end{array}$ & Thalidomide + PE & PE & $\mathrm{Y}$ & $\mathrm{N}$ & $\mathrm{N}$ & $\mathrm{Y}$ \\
\hline $\begin{array}{l}\text { Cheng et } \\
\text { al.2015 }\end{array}$ & China & $\mathrm{N}$ & $\geq 2$ & $28 / 28$ & $57.9 / 58.1$ & $\begin{array}{l}67.86 / \\
64.29\end{array}$ & $\mathrm{~N}$ & $\mathrm{~N}$ & Thalidomide + PI & PI & $\mathrm{Y}$ & $\mathrm{N}$ & $\mathrm{N}$ & $\mathrm{Y}$ \\
\hline $\begin{array}{l}\text { Liu et } \\
\text { al.2015 }\end{array}$ & China & $\mathrm{N}$ & $\mathrm{N}$ & $25 / 25$ & $52.45 / 54.63$ & $\begin{array}{l}32.00 / \\
24.00\end{array}$ & $\begin{array}{c}100.00 / \\
100.00\end{array}$ & $\begin{array}{l}44.00 / \\
28.00\end{array}$ & Thalidomide + PE & $\mathrm{PE}$ & $\mathrm{N}$ & $\mathrm{N}$ & $\mathrm{N}$ & $\mathrm{N}$ \\
\hline $\begin{array}{l}\text { Liu et } \\
\text { al.2013 }\end{array}$ & China & $\mathrm{N}$ & 2 & $12 / 12$ & $\mathrm{~N}$ & $\mathrm{~N}$ & $\begin{array}{c}100.00 / \\
100.00\end{array}$ & $\mathrm{~N}$ & Thalidomide + PI & PI & $\mathrm{Y}$ & $\mathrm{N}$ & $\mathrm{N}$ & $\mathrm{Y}$ \\
\hline $\begin{array}{l}\text { Pujol et } \\
\text { al.2007 }\end{array}$ & France & III & 1 & $49 / 43$ & $59.5 / 59.6$ & $\begin{array}{l}79.59 / \\
79.07\end{array}$ & $\begin{array}{l}100.00 / \\
100.00\end{array}$ & $\begin{array}{l}100.00 / \\
100.00\end{array}$ & Thalidomide + PCDE & placebo+PCDE & $\mathrm{N}$ & $\mathrm{Y}$ & $\mathrm{Y}$ & $\mathrm{Y}$ \\
\hline $\begin{array}{l}\text { Lee et } \\
\text { al.2009 }\end{array}$ & UK & III & 1 & $365 / 359$ & $65 / 65$ & $\begin{array}{l}57.81 / \\
55.99\end{array}$ & $\begin{array}{c}96.44 / \\
91.92\end{array}$ & $\begin{array}{l}51.51 / \\
46.80\end{array}$ & Thalidomide + EC & placebo + EC & $\mathrm{N}$ & $\mathrm{Y}$ & $\mathrm{Y}$ & $\mathrm{Y}$ \\
\hline $\begin{array}{l}\text { Arnold et } \\
\text { al.2007 }\end{array}$ & Canada & II & $\begin{array}{l}\text { mainten- } \\
\text { ance }\end{array}$ & $53 / 54$ & $56.9 / 62.4$ & $\begin{array}{c}50.94 / \\
57.41\end{array}$ & $\begin{array}{l}100.00 / \\
100.00\end{array}$ & $\begin{array}{c}56.60 / \\
57.41\end{array}$ & Vandetanib & placebo & $\mathrm{N}$ & $\mathrm{Y}$ & $\mathrm{Y}$ & $\mathrm{Y}$ \\
\hline
\end{tabular}

Abbreviations: N(A/C): number of patients (Angiogenesis inhibitors plus chemotherapy group/Chemotherapy alone group); PS: performance status; ACT: angiogenesis inhibitors plus chemotherapy; CT: chemotherapy; PE: cisplatin and etoposide; EC: etoposide and carboplatin; PCDE: cisplatin - cyclophosphamide - epidoxorubicin - etoposide; PT: cisplatin and topotecan; PI: cisplatin and irinotecan; ORR: objective response rate; OS: overall survival; PFS: progression-free survival; AEs: adverse events; N:no mention in the paper; Y: mentioned in the paper.

blinding methods and one [30] reported its allocation concealment. All trials applied the intent-to-treat analysis and underwent quality assessment. Eventually, fifteen [16$18,20-31]$ received B quality scores and one [19] received $\mathrm{C}$ quality score (Figure 2).

\section{Objective response rate}

Eleven eligible trials $[16,17,19-26,28]$ involved objective response rate (ORR), which was defined as the proportion of complete and partial responses among all evaluable patients. A fixed-effect model was utilized because heterogeneity did not exist $\left(I^{2}=0 \%\right)$. Notably, angiogenesis inhibitors plus chemotherapy group exhibited a superior ORR to chemotherapy alone group $(\mathrm{RR}=1.34 ; 95 \% \mathrm{CI}=1.19-1.51 ; P<0.00001)$ (Figure $3)$. The funnel plot indicated no significant publication bias on ORR (Figure 4). Additionally, subgroup analysis on angiogenesis inhibitors only targeting VEGF/VEGFR (Bevacizumab, Ziv-aflibercept, rh-Endostatin) also acquired a superior ORR $(\mathrm{RR}=1.36 ; 95 \% \mathrm{CI}=1.20-1.55$; $P<0.00001$ ) (Figure 3).

\section{Survival}

The overall survival (OS) was available in 7 trials $[16-19,29-31]$. Owing to the heterogeneity values $\left(I^{2}=\right.$ $0 \%$ ), a fixed-effect model was employed and the result showed no significant difference in OS between ACT group and $\mathrm{CT}$ group $(\mathrm{HR}=1.05 ; 95 \% \mathrm{CI}=0.94-1.17 ; P=$ 0.36 ) (Figure 5). Additionally, subgroup analysis showed that, compared with chemotherapy alone group, first-line treatment with angiogenesis inhibitors plus chemotherapy did not significantly lower mortality risk $(\mathrm{HR}=1.06$; $95 \% \mathrm{CI}=0.94-1.21 ; P=0.35$ ) (Figure 5). Meanwhile, compared with chemotherapy alone group, antibodies 


\begin{tabular}{|c|c|c|}
\hline & ACT-group (\%) N=956 (100\%) & CT-group (\%) N=942 (100\%) \\
\hline \multicolumn{3}{|l|}{ Sex } \\
\hline Male & $534(56 \%)$ & $539(57 \%)$ \\
\hline Female & $349(36 \%)$ & $327(35 \%)$ \\
\hline unknown & $73(8 \%)$ & $76(8 \%)$ \\
\hline \multicolumn{3}{|l|}{ ECOG PS } \\
\hline 0 & $138(14 \%)$ & $177(19 \%)$ \\
\hline 1 & $416(44 \%)$ & $385(41 \%)$ \\
\hline 2 & $121(13 \%)$ & $78(8 \%)$ \\
\hline 3 & $13(1 \%)$ & $29(3 \%)$ \\
\hline unknown & $268(28 \%)$ & $273(29 \%)$ \\
\hline \multicolumn{3}{|l|}{ Stage } \\
\hline Extensive & $556(58 \%)$ & $519(55 \%)$ \\
\hline Limited & $280(29 \%)$ & $295(31 \%)$ \\
\hline unknown & $120(13 \%)$ & $128(14 \%)$ \\
\hline
\end{tabular}

Table 3: Treatment regimens of trials included for analysis

\begin{tabular}{lcc}
\hline StudyID & Treatment regimens (each 21-day cycle) \\
\hline ACT group & CT group \\
\hline
\end{tabular}

Allen et al.2014 Ziv-aflibercept $6 \mathrm{mg} / \mathrm{kg}$ on day $1+$ topotecan 4 $\mathrm{mg} / \mathrm{m}^{2}$ on days 1,8 and 15

Spigel et al.2011 Bevacizumab $15 \mathrm{mg} / \mathrm{kg}$ on day $1+$ etoposide $100 \mathrm{mg} / \mathrm{m}^{2}$ on days $1-3+$ cisplatin $75 \mathrm{mg} / \mathrm{m}^{2}$ or carboplatin $\mathrm{AUC}=5 \mathrm{mg} / \mathrm{mL} / \mathrm{min}$ on day 1

Pujol et al.2015

Lu et al.2015

Luo et al.2013

Dai et al.2012

Li et al.2010
Bevacizumab $7.5 \mathrm{mg} / \mathrm{kg}$ on day $1+$ PS 0-1: 4'-epidoxorubicin $30 \mathrm{mg} / \mathrm{m}^{2}$; on day $1+$ cisplatin $75 \mathrm{mg} / \mathrm{m}^{2}$; on day $2+$ etoposide $75 \mathrm{mg}$ / $\mathrm{m}^{2}$; on days 1-3 + cyclophosphamide $300 \mathrm{mg} /$ $\mathrm{m}^{2}$; on days $1-3 / \mathrm{PS} 2$ : cisplatin $80 \mathrm{mg} / \mathrm{m}^{2}$; on day $2+$ etoposide $120 \mathrm{mg} / \mathrm{m}^{2}$; on days $1-3$

rh-Endostatin $7.5 \mathrm{mg} / \mathrm{m}^{2}$ on days $1-14+$ etoposide $60 \mathrm{mg} / \mathrm{m}^{2}$ on days 1-5 + carboplatin $\mathrm{AUC}=5 \mathrm{mg} / \mathrm{ml} / \mathrm{min}$ on day 1

rh-Endostatin $15 \mathrm{mg}$ on days 1-14 + etoposide $100 \mathrm{mg}$ on days $1-5+$ carboplatin $400-500 \mathrm{mg}$ on day 1

rh-Endostatin $15 \mathrm{mg}$ on days 1-14 + etoposide $100 \mathrm{mg} / \mathrm{m}^{2}$ on days $1-5+$ cisplatin $20 \mathrm{mg} / \mathrm{m}^{2}$; on days $2-5$

rh-Endostatin $15 \mathrm{mg}$ on days 1-14 + etoposide $100 \mathrm{mg} / \mathrm{m}^{2}$ on days $1-5+$ cisplatin $80 \mathrm{mg} / \mathrm{m}^{2}$; on day 2 topotecan $4 \mathrm{mg} / \mathrm{m}^{2}$ on days 1,8 and 15

placebo $15 \mathrm{mg} / \mathrm{kg}$ on day $1+$ etoposide 100 $\mathrm{mg} / \mathrm{m}^{2}$ on days $1-3+$ cisplatin $75 \mathrm{mg} / \mathrm{m}^{2}$ or carboplatin $\mathrm{AUC}=5 \mathrm{mg} / \mathrm{mL} / \mathrm{min}$ on day 1

PS 0-1: 4'-epidoxorubicin $30 \mathrm{mg} / \mathrm{m}^{2}$; on day 1 + cisplatin $75 \mathrm{mg} / \mathrm{m}^{2}$; on day $2+$ etoposide 75 $\mathrm{mg} / \mathrm{m}^{2}$; on days $1-3+$ cyclophosphamide 300 $\mathrm{mg} / \mathrm{m}^{2}$; on days $1-3 /$ PS 2: cisplatin $80 \mathrm{mg} / \mathrm{m}^{2}$; on day $2+$ etoposide $120 \mathrm{mg} / \mathrm{m}^{2}$; on days $1-3$

etoposide $60 \mathrm{mg} / \mathrm{m}^{2}$ on days $1-5+$ carboplatin $\mathrm{AUC}=5 \mathrm{mg} / \mathrm{ml} / \mathrm{min}$ on day 1

etoposide $100 \mathrm{mg}$ on days 1-5 + carboplatin 400-500 $\mathrm{mg}$ on day 1

etoposide $100 \mathrm{mg} / \mathrm{m}^{2}$ on days $1-5+$ cisplatin 20 $\mathrm{mg} / \mathrm{m}^{2}$; on days $2-5$

etoposide $100 \mathrm{mg} / \mathrm{m}^{2}$ on days $1-5+$ cisplatin 80 $\mathrm{mg} / \mathrm{m}^{2}$; on day 2

(Continued) 


\begin{tabular}{|c|c|c|}
\hline \multirow[t]{2}{*}{ StudyID } & \multicolumn{2}{|c|}{ Treatment regimens (each 21-day cycle) } \\
\hline & ACT group & CT group \\
\hline Wang et al.2011 & $\begin{array}{l}\text { rh-Endostatin } 15 \mathrm{mg} \text { on days } 1-14+\text { etoposide } \\
100 \mathrm{mg} \text { on days } 1-5+\text { cisplatin } 20 \mathrm{mg} \text { on days } \\
\qquad 2-5\end{array}$ & $\begin{array}{c}\text { etoposide } 100 \mathrm{mg} \text { on days } 1-5+\text { cisplatin } 20 \mathrm{mg} \\
\text { on days } 2-5\end{array}$ \\
\hline Hu et al.2011 & $\begin{array}{c}\text { rh-Endostatin } 15 \mathrm{mg} \text { on days } 1-14+\text { topotecan } \\
0.75-1.00 \mathrm{mg} / \mathrm{m}^{2} \text { on days } 1-5+\text { cisplatin } 25 \mathrm{mg} / \\
\mathrm{m}^{2} \text {; on days } 1-3\end{array}$ & $\begin{array}{l}\text { topotecan } 0.75-1.00 \mathrm{mg} / \mathrm{m}^{2} \text { on days } 1-5+ \\
\text { cisplatin } 25 \mathrm{mg} / \mathrm{m}^{2} \text {; on days } 1-3\end{array}$ \\
\hline Liu et al.2011 & $\begin{array}{c}\text { Thalidomide } 100 \mathrm{mg} / \mathrm{d} \text { daily }+ \text { etoposide } 100 \\
\mathrm{mg} / \mathrm{m}^{2} \text {; on days } 1-3+\text { cisplatin } 30 \mathrm{mg} / \mathrm{m}^{2} ; \text { on } \\
\text { days } 1-3\end{array}$ & $\begin{array}{l}\text { etoposide } 100 \mathrm{mg} / \mathrm{m}^{2} ; \text { on days } 1-3+\text { cisplatin } \\
\qquad 30 \mathrm{mg} / \mathrm{m}^{2} ; \text { on days } 1-3\end{array}$ \\
\hline Cheng et al.2015 & $\begin{array}{c}\text { Thalidomide } 150 \mathrm{mg} / \mathrm{d} \text { daily }+ \text { cisplatin } 25 \mathrm{mg} / \\
\mathrm{m}^{2} \text { on days } 1-3+\text { irinotecan } 125 \mathrm{mg} / \mathrm{m}^{2} \text { on days } \\
1,8\end{array}$ & $\begin{array}{c}\text { cisplatin } 25 \mathrm{mg} / \mathrm{m}^{2} \text { on days } 1-3+\text { irinotecan } 125 \\
\mathrm{mg} / \mathrm{m}^{2} \text { on days } 1,8\end{array}$ \\
\hline Liu et al.2015 & $\begin{array}{c}\text { Thalidomide } 100 \mathrm{mg} / \mathrm{d} \text { daily }+ \text { etoposide } 100 \\
\mathrm{mg} / \mathrm{m}^{2} \text {; on days } 1-3+\text { cisplatin } 30 \mathrm{mg} / \mathrm{m}^{2} ; \text { on } \\
\text { days } 1-3\end{array}$ & $\begin{array}{l}\text { etoposide } 100 \mathrm{mg} / \mathrm{m}^{2} ; \text { on days } 1-3+\text { cisplatin } \\
30 \mathrm{mg} / \mathrm{m}^{2} ; \text { on days } 1-3\end{array}$ \\
\hline Liu et al.2013 & $\begin{array}{c}\text { Thalidomide } 100 \mathrm{mg} / \mathrm{d} \text { daily }+ \text { cisplatin } 25 \mathrm{mg} / \\
\mathrm{m}^{2} \text { on days } 1-3+\text { irinotecan } 60 \mathrm{mg} / \mathrm{m}^{2} \text { on days } \\
1,8\end{array}$ & $\begin{array}{c}\text { cisplatin } 25 \mathrm{mg} / \mathrm{m}^{2} \text { on days } 1-3+\text { irinotecan } 60 \\
\mathrm{mg} / \mathrm{m}^{2} \text { on days } 1,8\end{array}$ \\
\hline Pujol et al.2007 & $\begin{array}{c}\text { Thalidomide } 100-400 \mathrm{mg} / \mathrm{d}+4^{\prime} \text {-epidoxorubicin } \\
40 \mathrm{mg} / \mathrm{m}^{2} \text { on day } 1+\text { cisplatin } 100 \mathrm{mg} / \mathrm{m}^{2} \text { on } \\
\text { day } 2+\text { etoposide } 100 \mathrm{mg} / \mathrm{m}^{2} \text { on days } 1-3+ \\
\text { cyclophosphamide } 400 \mathrm{mg} / \mathrm{m}^{2} \text { on days } 1-3 \\
\text { (every } 28 \text { days) }\end{array}$ & $\begin{array}{c}\text { placebo } 100-400 \mathrm{mg} / \mathrm{d}+4^{\prime} \text {-epidoxorubicin } \\
40 \mathrm{mg} / \mathrm{m}^{2} \text { on day } 1+\text { cisplatin } 100 \mathrm{mg} / \mathrm{m}^{2} \text { on } \\
\text { day } 2+\text { etoposide } 100 \mathrm{mg} / \mathrm{m}^{2} \text { on days } 1-3+ \\
\text { cyclophosphamide } 400 \mathrm{mg} / \mathrm{m}^{2} \text { on days } 1-3 \\
\text { (every } 28 \text { days) }\end{array}$ \\
\hline Lee et al.2009 & $\begin{array}{c}\text { Thalidomide } 100-200 \mathrm{mg} / \mathrm{d}+\text { etoposide } 120 \\
\mathrm{mg} / \mathrm{m}^{2} \text { on day } 1 \text { and } 200 \mathrm{mg} \text { on days } 2-3+ \\
\text { carboplatin AUC }=5 \mathrm{mg} / \mathrm{ml} / \mathrm{min} \text { (extensive- } \\
\text { stage) or AUC }=6 \mathrm{mg} / \mathrm{ml} / \mathrm{min} \text { (limited-stage) } \\
\text { on day } 1\end{array}$ & $\begin{array}{l}\text { placebo } 100-200 \mathrm{mg} / \mathrm{d}+\text { etoposide } 120 \mathrm{mg} / \mathrm{m}^{2} \\
\text { on day } 1 \mathrm{and} 200 \mathrm{mg} \text { on days } 2-3+\text { carboplatin } \\
\text { AUC }=5 \mathrm{mg} / \mathrm{ml} / \mathrm{min} \text { (extensive-stage) or AUC } \\
\quad=6 \mathrm{mg} / \mathrm{ml} / \mathrm{min} \text { (limited-stage) on day } 1\end{array}$ \\
\hline Arnold et al.2007 & Vandetanib $300 \mathrm{mg} / \mathrm{d}$ daily & placebo $300 \mathrm{mg} / \mathrm{d}$ daily \\
\hline
\end{tabular}

Abbreviations: ACT: angiogenesis inhibitors plus chemotherapy; CT: chemotherapy; AUC: area under the curve.

targeting VEGF $(\mathrm{HR}=1.05 ; 95 \% \mathrm{CI}=0.87-1.27 ; P=$ 0.60 ) (Figure 5) or small molecule angiogenesis inhibitors $(\mathrm{HR}=1.05 ; 95 \% \mathrm{CI}=0.92-1.20 ; P=0.46)($ Figure 5$)$ plus chemotherapy group also did not significantly lower mortality risk. Seven trials [16-19, 29-31] reporting PFS were analyzed via a random-effects model based on the heterogeneity values $\left(I^{2}=53 \%\right)$ and revealed that, compared with chemotherapy alone, angiogenesis inhibitors plus chemotherapy slightly prolonged PFS $(\mathrm{HR}=0.86 ; 95 \% \mathrm{CI}=0.73-1.01 ; P=0.07$ ) (Figure 6). Angiogenesis inhibitors in first-line setting had no benefits in PFS (HR $=0.86 ; 95 \% \mathrm{CI}=0.69-1.07 ; P=0.18)$ (Figure 6). Subgroup analysis showed that, compared with chemotherapy alone, the addition of antibodies targeting VEGF significantly prolonged PFS ( $\mathrm{HR}=0.76 ; 95 \% \mathrm{CI}$ $=0.64-0.90 ; P=0.001)($ Figure 7$)$ while the addition of small molecular receptor tyrosine kinase inhibitors yielded no benefits in PFS (HR $=0.98 ; 95 \% \mathrm{CI}=0.87-1.11 ; P$
$=0.78$ ) (Figure 7). Additionally, subgroup analysis on angiogenesis inhibitors only targeting VEGF/VEGFR (Bevacizumab, Ziv-aflibercept, rh-Endostatin) also acquired a superior PFS $(\mathrm{HR}=0.77 ; 95 \% \mathrm{CI}=0.66-0.89$; $P=0.0007$ ) (Figure 7).

\section{Adverse events}

Fourteen included trials [16-23, 25, 26, 28-31] with sufficient data of treatment-related toxicity and severe AEs grading were applied to analyze AEs (Grade $\geq 3$ ). Severe hematotoxicity was the most common AEs without a significant difference between ACT and CT group (Figure 8). On the other hand, the most common non-hematologic AEs were largely mild and tolerable without a significant difference between two arms, with the exception that more patients in ACT group had gastrointestinal symptom $(\mathrm{RR}=$ $1.51 ; 95 \% \mathrm{CI}=1.15-1.98 ; P=0.003)$, hypertension $(\mathrm{RR}=$ 
2.62; 95\% CI $=1.30-5.28 ; P=0.007)$, metabolic disorders $(\mathrm{RR}=2.21 ; 95 \% \mathrm{CI}=1.02-4.81 ; P=0.04)$, neurology $(\mathrm{RR}=2.57 ; 95 \% \mathrm{CI}=1.30-5.09 ; P=0.007)$ or pain $(\mathrm{RR}$ $=6.12 ; 95 \% \mathrm{CI}=1.10-34.13 ; P=0.04)($ Figure 9,10$)$.

\section{DISCUSSION}

To our best knowledge, this study is the only metaanalysis to investigate antiangiogenic therapy in SCLC. Antiangiogenic agents consist mainly of antibodies (bevacizumab, ziv-aflibercept) and small molecules agents (rh-endostatin, vandetanib and thalidomide). The antibodies 'deactivate' VEGF via binding to them and blocking their bond to relevant receptors [32], while small molecules agents directly inhibit the kinase activity of VEGFR by competitively binding to receptor tyrosine kinases [33]. This study showed that the addition of angiogenesis inhibitors to chemotherapy possessed a significant benefit in terms of ORR, slightly prolonged the median PFS. Indeed, some small molecules agents analyzed in this study

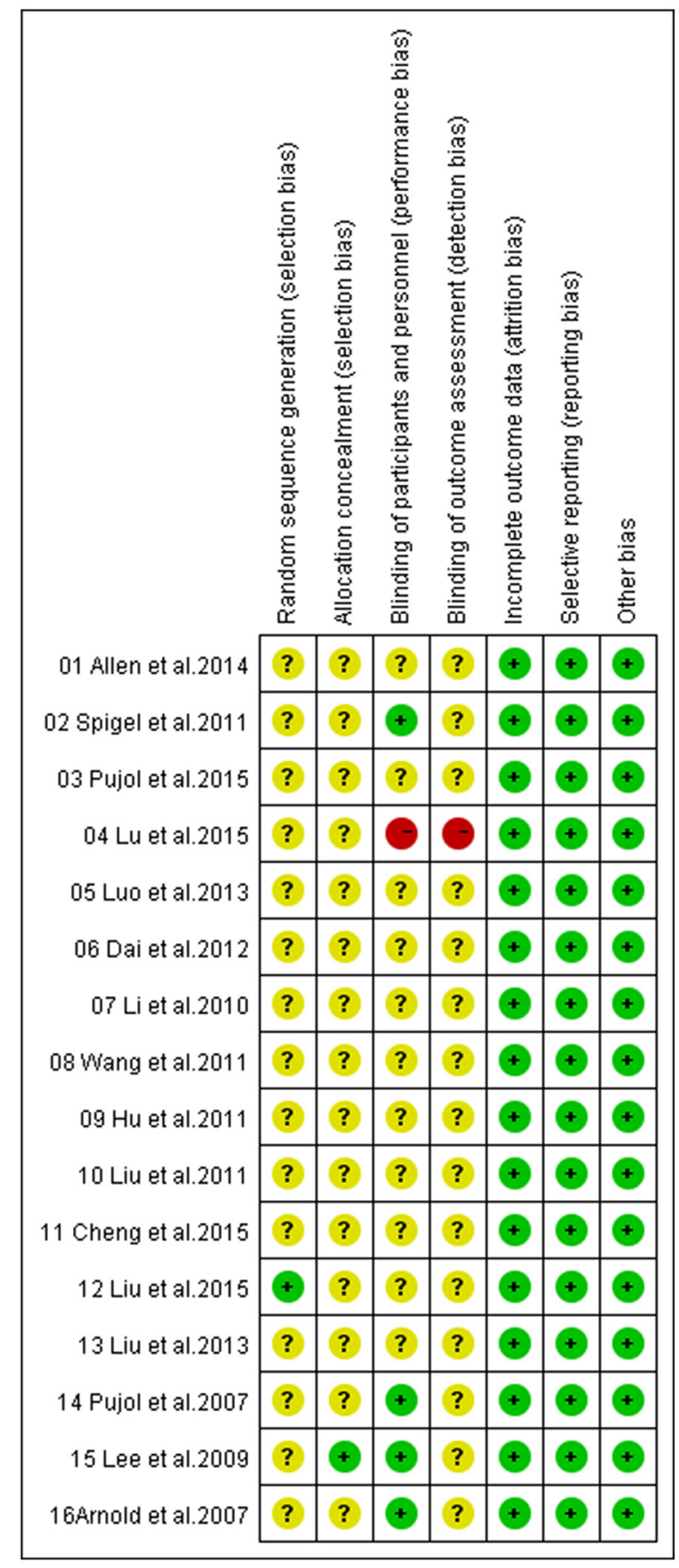

Figure 2: Bias risk and quality assessment of included studies. 
$\begin{array}{llll}\text { ACT group } & \text { CT group Risk Ratio Ratio }\end{array}$

Study or Subqroup Events Total Events Total Weight $\mathrm{M}-\mathrm{H}$. Fixed, $95 \% \mathrm{Cl}$

M-H, Fixed, $95 \% \mathrm{Cl}$

A 1.1.1 ORR

$\begin{array}{lllllll}01 \text { Allen et al.2014 } & 2 & 92 & 0 & 87 & 0.3 \% & 4.73[0.23,97.18]\end{array}$

$\begin{array}{lllllll}02 & \text { Spigel et al.2011 } \quad 30 & 52 & 24 & 50 & 13.7 \% & 1.20[0.83,1.74]\end{array}$

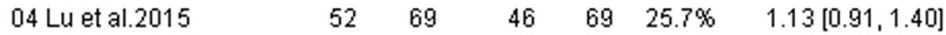

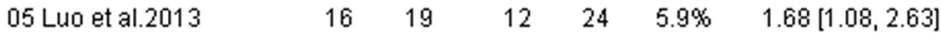

06 Dai et al.2012 $\quad 32 \quad 50 \quad 19 \quad 50 \quad 10.6 \% \quad 1.68[1.12,2.54]$

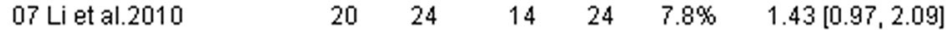

$\begin{array}{lllllll}08 \text { Wang et al.2011 } \quad 14 & 20 & 9 & 20 & 5.0 \% & 1.56[0.89,2.73]\end{array}$

$09 \mathrm{Hu}$ et al.2011 $\quad 38 \quad 45 \quad 27 \quad 44 \quad 15.3 \% \quad 1.38[1.05,1.80]$

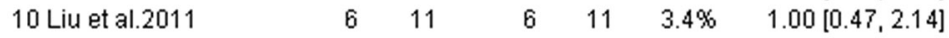

$\begin{array}{lllllll}11 \text { Cheng et al.2015 } & 24 & 28 & 18 & 28 & 10.1 \% & 1.33[0.97,1.83]\end{array}$

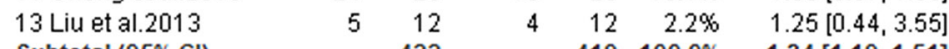

Subtotal $(95 \% \mathrm{CI})$

Total events

239

$419 \quad 100.0 \% \quad 1.34[1.19,1.51]$

Heterogeneity: $\mathrm{Chi}^{2}=6.64, \mathrm{df}=10(P=0.76) ; \mathrm{I}^{2}=0 \%$

Test for overall effect: $Z=4.90(P<0.00001)$

B 1.1.2 ORR: angiogenesis inhibitors only targeting VEGF/NEGFR + CT vs CT

01 Allen et al.2014

02 Spigel et al.2011

$\begin{array}{rr}2 & 92 \\ 30 & 52\end{array}$

04 Lu et al. 2015

05 Luo et al.2013

06 Dai et al. 2012

0 . Li et al. 2010

08 Wang et al.2011

$09 \mathrm{Hu}$ et al. 2011

Subtotal $(95 \% \mathrm{Cl})$

Total events

$52 \quad 69$

$16 \quad 19$

3250

$20 \quad 24$

1420

$38 \quad 45$

371

Heterogeneity: $\mathrm{Chi}^{2}=6.15, \mathrm{df}=7(P=0.52) ; \mathrm{I}^{2}=0 \%$

Test for overall effect: $Z=4.68$ ( $P<0.00001$ )

$\begin{array}{rrrr}0 & 87 & 0.3 \% & 4.73[0.23,97.18] \\ 24 & 50 & 16.2 \% & 1.20[0.83,1.74] \\ 46 & 69 & 30.5 \% & 1.13[0.91,1.40] \\ 12 & 24 & 7.0 \% & 1.68[1.08,2.63] \\ 19 & 50 & 12.6 \% & 1.68[1.12,2.54] \\ 14 & 24 & 9.3 \% & 1.43[0.97,2.09] \\ 9 & 20 & 6.0 \% & 1.56[0.89,2.73] \\ 27 & 44 & 18.1 \% & 1.38[1.05,1.80] \\ & 368 & 100.0 \% & 1.36[1.20,1.55]\end{array}$

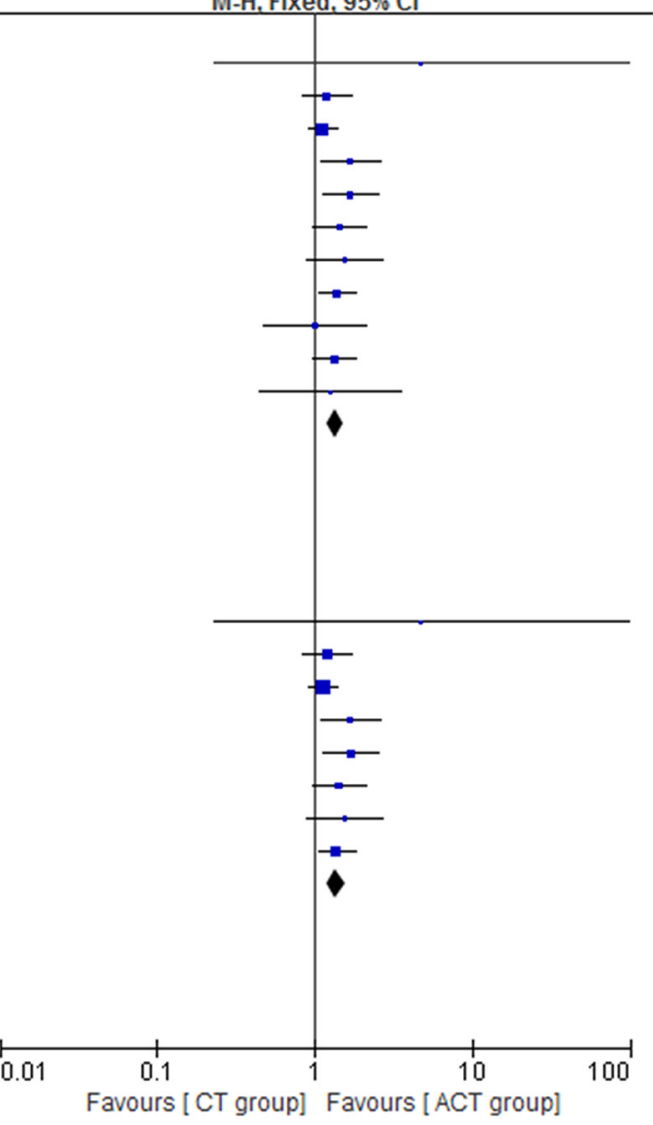

Figure 3: A. Objective response rate (ORR) of the studies; B. Subgroup analysis of ORR for angiogenesis inhibitors only targeting VEGF/ VEGFR plus chemotherapy (CT) versus CT.

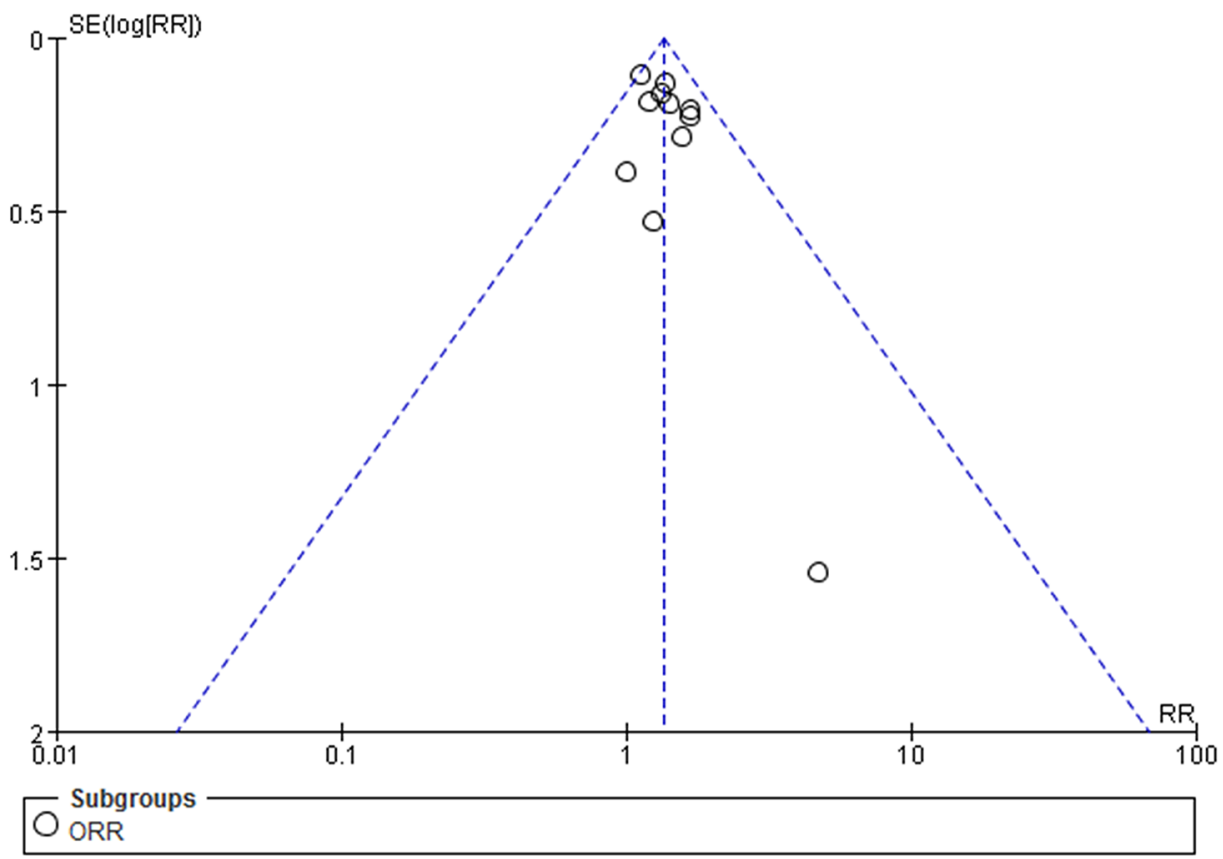

Figure 4: Funnel plot of ORR for included studies. 
were mainly multikinase-inhibitors (e.g. vandetanib: EGFR VEGFR RET) or substances (e.g. thalidomide) which affected a lot of cellular processes and antiangiogenesis was only part of anti-cancer mechanisms [34-37]. Thus the benefits of ORR and PFS could not be clearly attributed to anti-angiogenetic effect. Therefore, we conducted subgroup analysis on angiogenesis inhibitors only targeting VEGF/VEGFR (Bevacizumab, Ziv-aflibercept, rh-Endostatin). The results showed that anti-angiogenetic effect played a critical role in improving ORR and PFS. However, the improvement of ORR and PFS failed to translate into an OS benefit. One possible explanation was that the activation of alternative pro-angiogenic factors swiftly counteracted the effect of angiogenesis inhibitors; another was intrinsic or pre-existing resistance [38]. Considering the fundamental distinction between small molecule angiogenesis inhibitors and antibodies targeting VEGF in many aspects, we further conducted a subgroup analysis of both groups. The results showed that, compared with chemotherapy alone, neither antibodies targeting VEGF nor small molecule angiogenesis inhibitors plus chemotherapy significantly lowered mortality risk. Encouragingly, subgroup analysis exhibited that antibodies targeting VEGF plus chemotherapy significantly prolonged PFS for patients with SCLC. A reasonable explanation was that chemotherapy failed to inhibit angiogenesis in the presence of a reactive resistance, which was mediated by the HIF-1/VEGF pathway in cancer cells, while antibodies

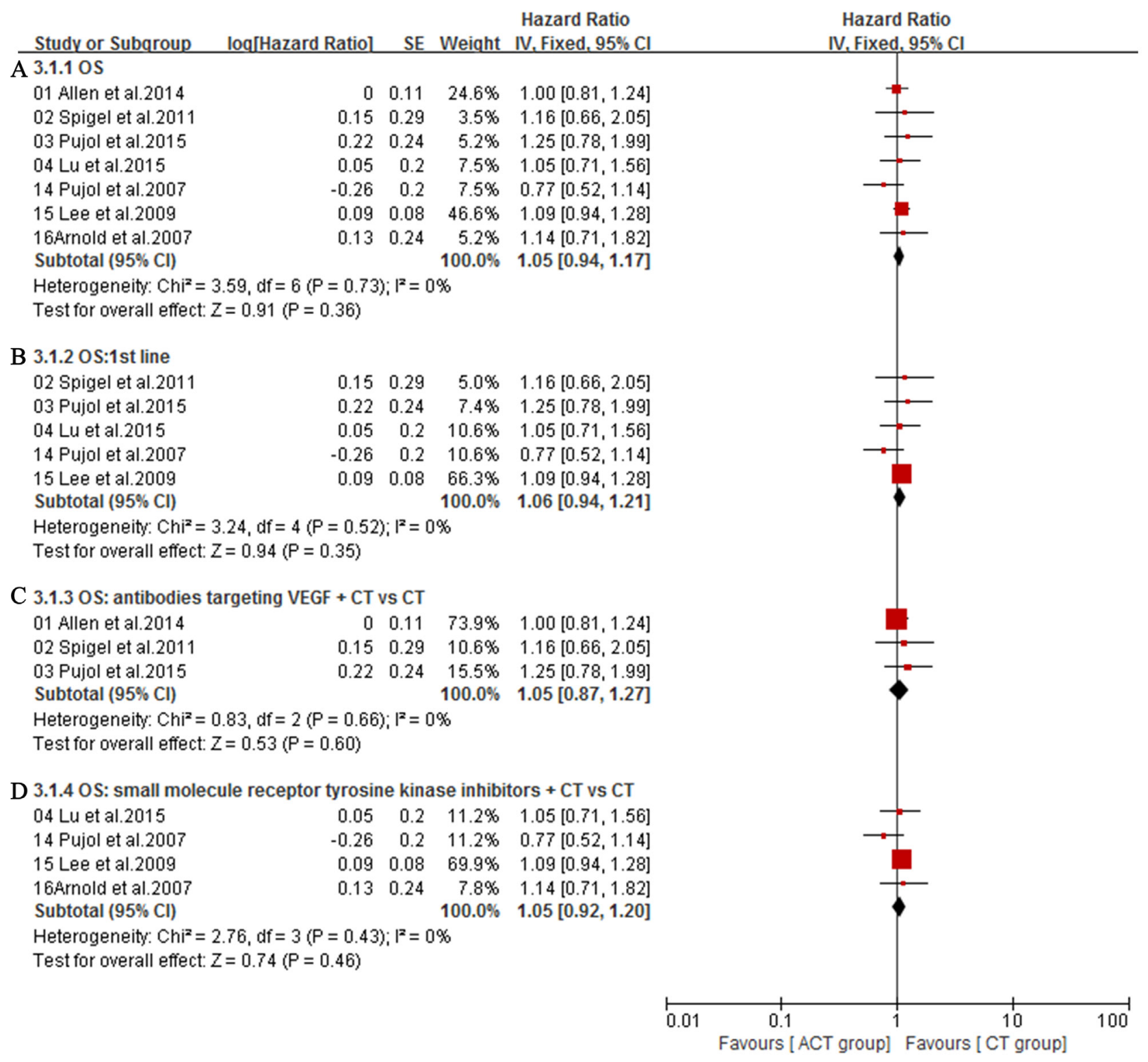

Figure 5: A. Overall survival (OS) of the studies; B. Subgroup analysis of the effect of angiogenesis inhibitors on OS in first-line settings; C. Subgroup analysis of OS for antibodies targeting VEGF plus CT versus CT; D. Subgroup analysis of OS for small molecule angiogenesis inhibitors plus CT versus CT. 


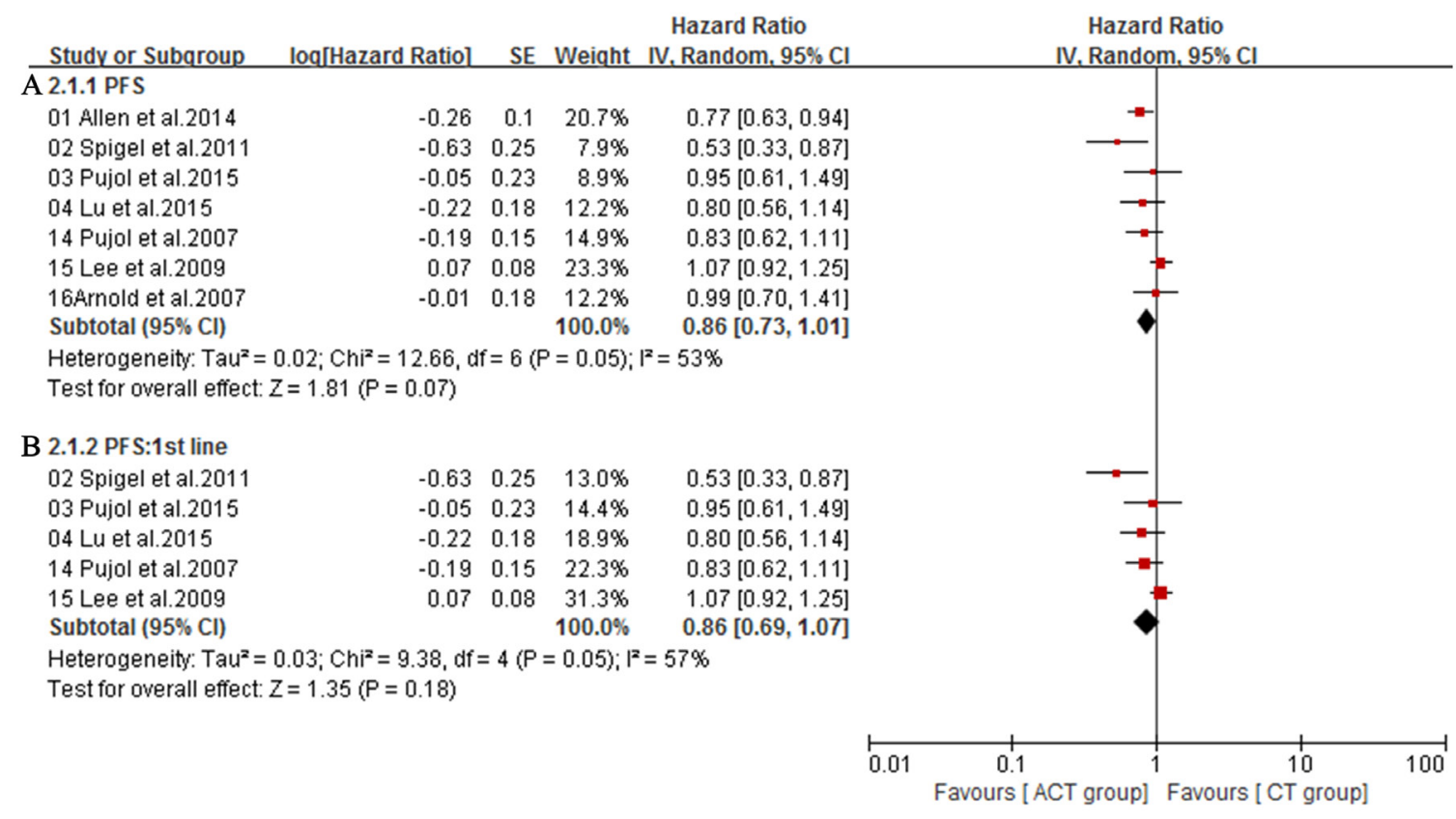

Figure 6: A. Progression-free survival (PFS) of the studies; B. Subgroup analysis of the effect of angiogenesis inhibitors on PFS in firstline settings.

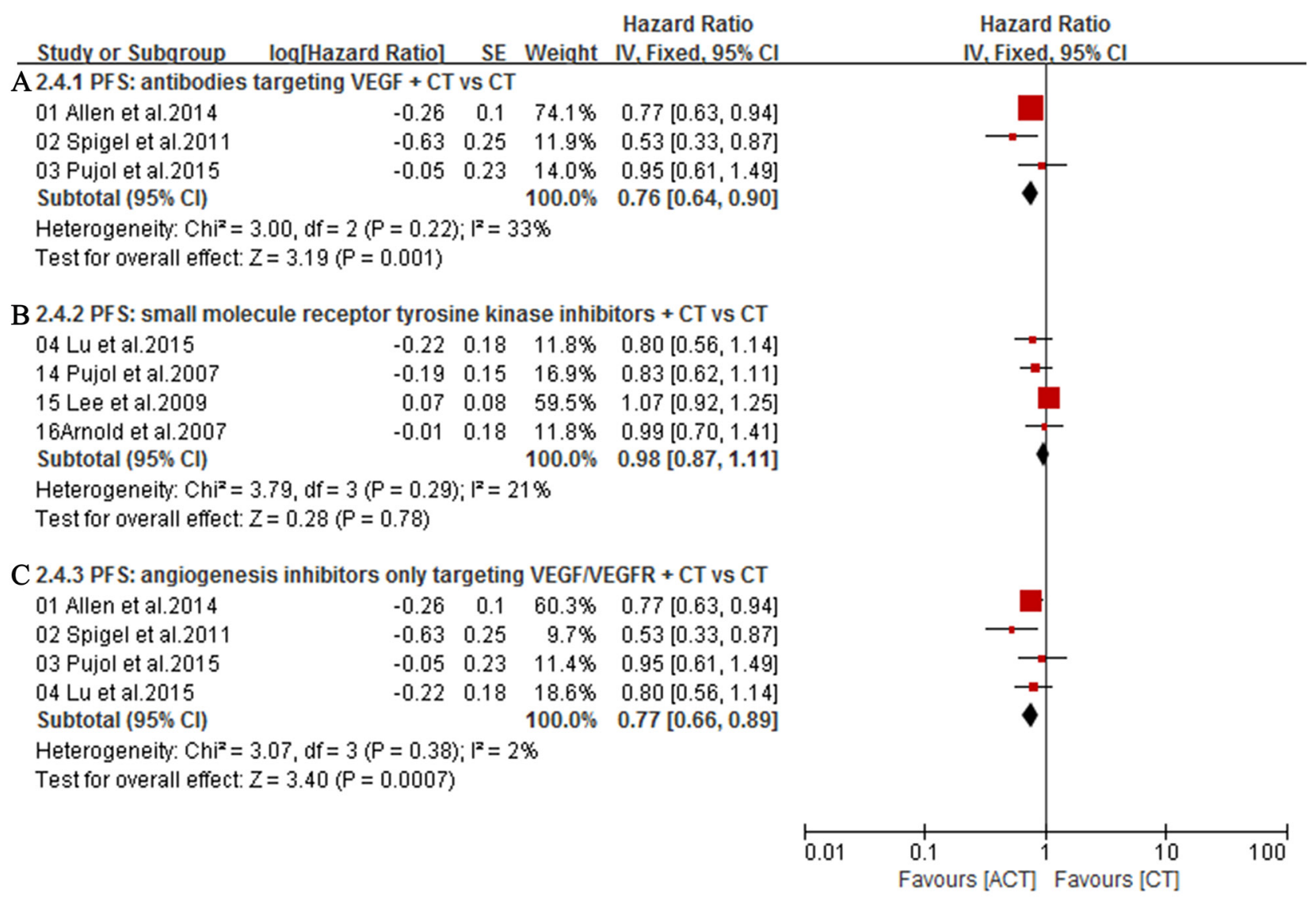

Figure 7: A. Subgroup analysis of PFS for antibodies targeting VEGF plus CT versus CT; B. Subgroup analysis of PFS for small molecule angiogenesis inhibitors plus CT versus CT; C. Subgroup analysis of PFS for angiogenesis inhibitors only targeting VEGF/VEGFR plus CT versus $\mathrm{CT}$. 
targeting VEGF blocked the reactive resistance, sensitizing cancer cells to chemotherapy [39].

VEGF is also a key mediator of angiogenesis in healthy tissues. VEGF may induce vasodilation by stimulating the release of nitric oxide in endothelial cells [40]. Therefore, inhibition of VEGF may lead to vasoconstriction and result in an increased peripheral vascular resistance [41]. Consequently, the use of angiogenesis inhibitors can lead to vascular disturbances which are the main factor behind the AEs of these drugs [42]. Our study showed that the addition of angiogenesis inhibitors would increase some common adverse events, such as pain, gastrointestinal symptom, hypertension, metabolic disorders and neurology.
Nevertheless, this study confronted following limitations: (i) eligible trials adopted several kinds of antiangiogenic agents; (ii) clinical characteristics such as ECOG performance status as well as stage were not completely equivalent; (iii) trials were mainly conducted in a molecularly unselected population. Thus, it impeded us to conduct a sub-analysis of potential predictive biomarkers to identify the exact benefit population.

Briefly, compared with chemotherapy alone, antibodies targeting VEGF plus chemotherapy significantly improved ORR and prolonged PFS with an acceptable toxicity profile for patients with SCLC. Therefore, angiogenesis inhibitors, especially antibodies

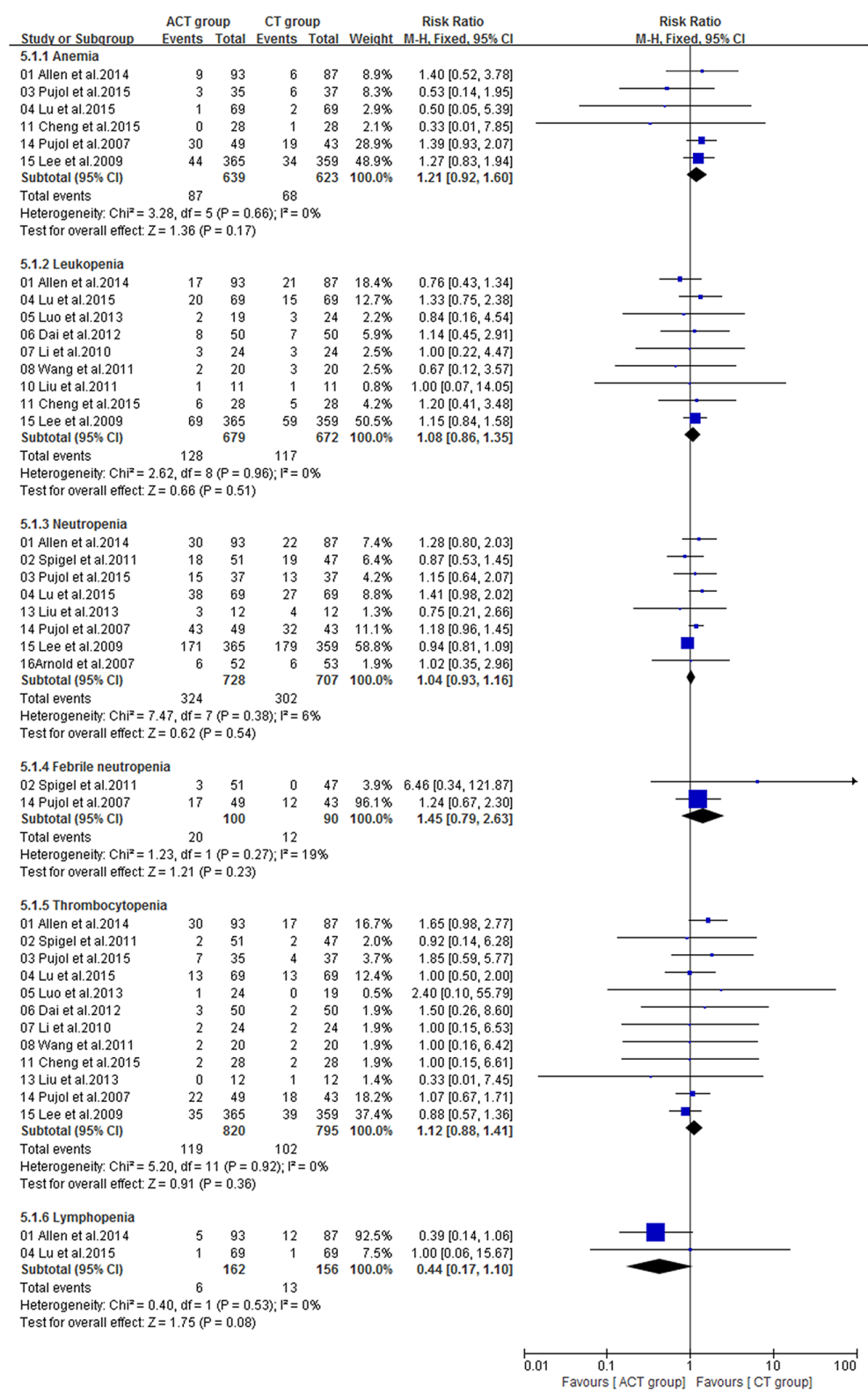

Figure 8: Severe hematologic toxicities of the studies. 


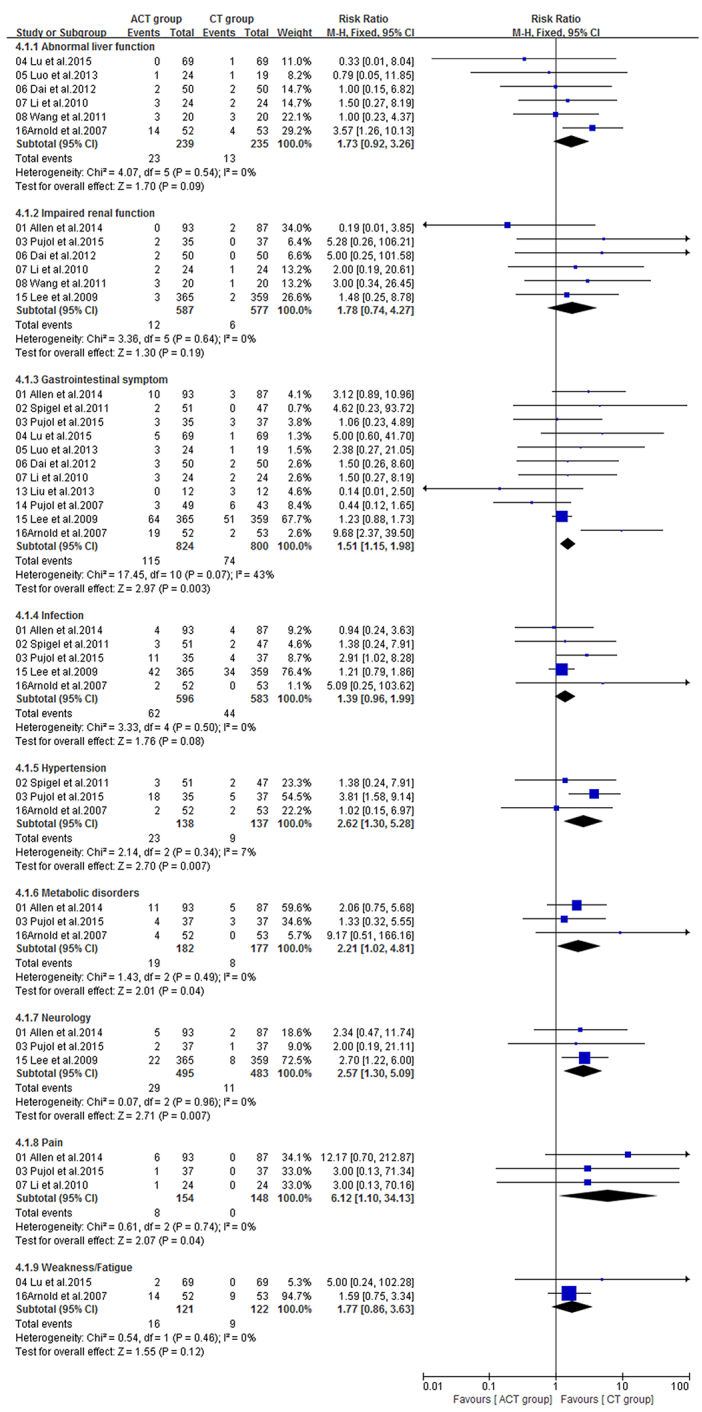

Figure 9: Severe nonhematologic toxicities of the studies (Part 1).

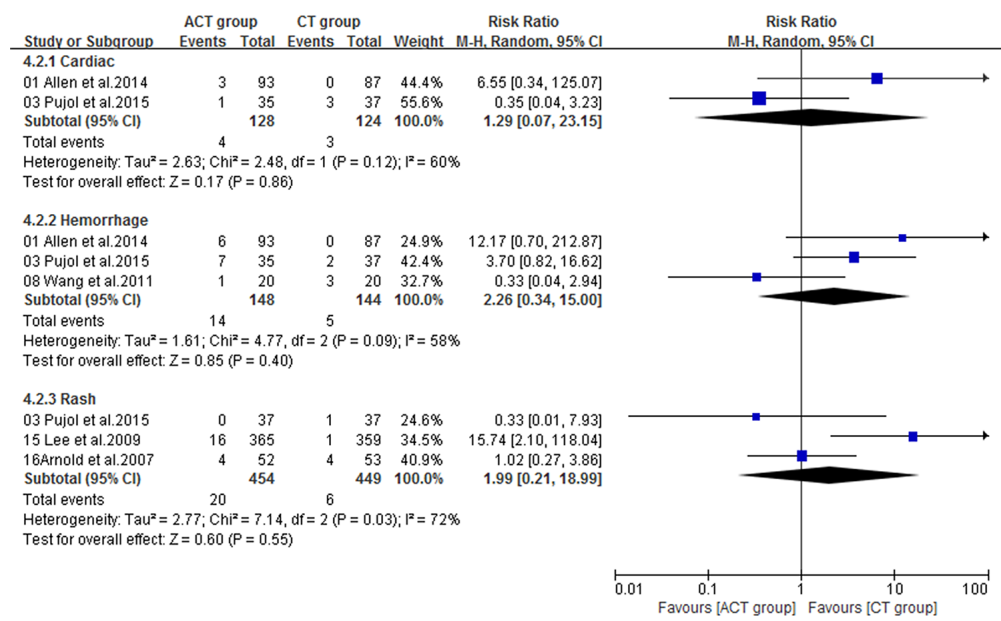

Figure 10: Severe nonhematologic toxicities of the studies (Part 2). 
targeting VEGF, combining with chemotherapy may be a potential promising strategy in managing SCLC.

\section{METHODS}

\section{Data sources and search}

Two authors ( $\mathrm{Lin} \mathrm{H}$ and $\mathrm{Li} \mathrm{LN}$ ) independently carried out a comprehensive systematic search for published articles in PubMed, EMBASE, Cochrane Library and Wanfang Data (a literature search database from China) without language restriction from inception to March 2016, in accordance with PRISMA (Preferred Reporting Items for Systematic Reviews and MetaAnalyses) guidelines [43], using following keywords and Mesh terms: "("angiogenesis inhibitors" [all fields] OR "antiangiogenesis" [all fields] OR "antiangiogenic agents" [all fields]) AND ("ziv-aflibercept" [all fields]) AND ("bevacizumab" [all fields]) AND ("rh-Endostatin" [all fields]) AND ("thalidomide" [all fields]) AND ("vandetanib" [all fields]) AND ("chemotherapy" [all fields]) AND ("small cell lung cancer" [Mesh] OR "SCLC" [Mesh])". Reviews, preclinical and animal trials were excluded.

\section{Study Selection}

The inclusion criteria were as follows: (i) RCT or clinical controlled trails with voluntarily enrolled patients; (ii) all participants had been histologically or cytologically confirmed; (iii) the trials involving angiogenesis inhibitors plus chemotherapy versus chemotherapy alone; (iv) trials excluded patients with double or multiple primary cancer or presence of unstable systemic disease; (v) trials evaluated at least one of ORR, OS, PFS and severe AEs (Grade $\geq 3$ ); (vi) response rate was determined using the Response Evaluation Criteria in Solid Tumors (RECIST 1.0 or 1.1 standards) [44] or WHO criteria [45]; (vii) adverse events were evaluated according to the National Cancer Institute Common Terminology Criteria for Adverse Events (CTCAE 2.0 or 3.0) [46] or WHO criteria [45].

\section{Data extraction and quality assessment}

Data were extracted independently by two reviewers ( $\mathrm{Lin} \mathrm{H}$ and $\mathrm{Li} \mathrm{LN}$ ), and any disagreements between the two reviewers were resolved by consensus involving a third reviewer (Xie XH). For each selected publication, we extracted the following items: first author, year of publication, country of original trial, trial phase, line of treatment, number of patients, demographics, clinical parameters, stage at initial diagnosis, interventions and outcomes. To assess study quality and applicability, we used the checklists of The Cochrane Handbook for Systematic Reviews of intervention (Version 5.1.0), based on the following criteria: (i) Random sequence generation; (ii) Allocation concealment; (iii) Blinding of participants and personnel; (iv) Blinding of outcome assessment; (v) Incomplete outcome data; (vi) Selective reporting; (vii) Other bias. Each trial for bias based on the criteria listed above was marked as 'low risk', 'high risk' or 'unclear risk'. Trials quality was defined as following: A rating: meeting all criteria of low risk; $B$ rating: meeting one or more criteria of unclear risk without high risk; $\mathrm{C}$ rating: appearing one or more criteria of high risk.

\section{Statistical analysis}

Statistical analysis was performed using RevMan 5.3 software (Cochrane Collaboration's Information Management System). Analysis of data comprised pooled risk ratio (RR) for dichotomous endpoints (e.g ORR, severe AEs), using the Mantel-Haenszel method [47]. The events and total number of patients from ACT group and CT group in the trials for ORR and severe AEs were extracted from the trials. OS and PFS were calculated using effect variables and expressed by hazard ratio (HR). HRs with $95 \%$ confidence intervals (CI) were directly extracted from trials or from the survival curves using the methods described by Tierney et al. [48] for OS and PFS when HRs were unavailable. The $95 \%$ CIs were calculated and presented in forest plots. Two-sided $P$ values less than 0.05 were considered statistically significant. Statistical heterogeneity of different trials was evaluated with the $I$ square tests [49]; no heterogeneity existed when $I^{2}<50 \%$, a fixed-effect model was applied to pool the study results. Significant heterogeneity was found if $I^{2}>50 \%$, and a random-effects statistical model was used [50]. The risk of publication bias was evaluated via visual appraisal of funnel plots.

\section{CONFLICTS OF INTEREST}

There is no conflict of interest.

\section{REFERENCES}

1. Siegel R, Ma J, Zou Z, Jemal A. Cancer statistics, 2014. Cancer J Clin. 2014; 64:9-29.

2. NCCN Clinical Practice Guidelines in Oncology, Version 1. http://www.ncen.org/professionals/physician_gls/f_ guidelines.asp.

3. Noda K, Nishiwaki Y, Kawahara M, Negoro S, Sugiura T, Yokoyama A, Fukuoka M, Mori K, Watanabe K, Tamura T, Yamamoto S, Saijo N; Japan Clinical Oncology Group. Irinotecan plus cisplatin compared with etoposide plus cisplatin for extensive small-cell lung cancer. N Engl J Med. 2002; 346:85-91.

4. Hanna N, Bunn PA Jr, Langer C, Einhorn L, Guthrie T Jr, Beck T, Ansari R, Ellis P, Byrne M, Morrison M, 
Hariharan S, Wang B, Sandler A. Randomized phase III trial comparing irinotecan/cisplatin with etoposide/ cisplatin in patients with previously untreated extensivestage disease small-cell lung cancer. J Clin Oncol. 2006; 24:2038-43.

5. Hermes A, Bergman B, Bremnes R, Ek L, Fluge S, Sederholm C, Sundstrøm S, Thaning L, Vilsvik J, Aasebø $\mathrm{U}$, Sörenson S. Irinotecan plus carboplatin versus oral etoposide plus carboplatin in extensive small-cell lung cancer: a randomized phase III trial. J Clin Oncol. 2008; 26:4261-7.

6. Albain KS, Crowley JJ, LeBlanc M, Livingston RB. Determinants of improved outcome in small-cell lung cancer: an analysis of the 2,580-patient Southwest Oncology Group data base. J Clin Oncol 1990; 8: 1563-1574.

7. Folkman J. Role of angiogenesis in tumor growth and metastasis. Semin Oncol. 2002; 29:15-8.

8. Zhao L, Li W, Zhang H, Hou N, Guo L, Gao Q. Angiogenesis inhibitors rechallenge in patients with advanced non-small-cell lung cancer: a pooled analysis of randomized controlled trials. Onco Targets Ther. 2015; 8: 2775-81.

9. Sheng J, Yang YP, Yang BJ, Zhao YY, Ma YX, Hong SD, Zhang YX, Zhao HY, Huang Y, Zhang L. Efficacy of Addition of Antiangiogenic Agents to Taxanes-Containing Chemotherapy in Advanced Nonsmall-Cell Lung Cancer: A Meta-Analysis and Systemic Review. Medicine (Baltimore). 2015; 94:e1282.

10. Hong S, Tan M, Wang S, Luo S, Chen Y, Zhang L. Efficacy and safety of angiogenesis inhibitors in advanced non-small cell lung cancer: a systematic review and meta-analysis. J Cancer Res Clin Oncol. 2015; 141:909-21.

11. Niell HB, Herndon JE 2nd, Miller AA, Watson DM, Sandler AB, Kelly K, Marks RS, Perry MC, Ansari RH, Otterson G, Ellerton J, Vokes EE, Green MR; Cancer and Leukemia Group. Randomized phase III intergroup trial of etoposide and cisplatin with or without paclitaxel and granulocyte colony-stimulating factor in patients with extensive-stage small-cell lung cancer: Cancer and Leukemia Group B Trial 9732. J Clin Oncol 2005; 23: 3752-3759.

12. Spigel DR, Greco FA, Zubkus JD, Murphy PB, Saez RA, Farley C, Yardley DA, Burris HA 3rd, Hainsworth JD. Phase II trial of irinotecan, carboplatin, and bevacizumab in the treatment of patients with extensive-stage small-cell lung cancer. J Thorac Oncol. 2009; 4: 1555-60.

13. Ready NE, Dudek AZ, Pang HH, Hodgson LD, Graziano SL, Green MR, Vokes EE. Cisplatin, irinotecan, and bevacizumab for untreated extensive-stage small-cell lung cancer: CALGB 30306, a phase II study. J Clin Oncol. 2011; 29:4436-41.

14. Horn L, Dahlberg SE, Sandler AB, Dowlati A, Moore DF, Murren JR, Schiller JH. Phase II study of cisplatin plus etoposide and bevacizumab for previously untreated, extensive-stage small-cell lung cancer: Eastern Cooperative Oncology Group Study E3501. J Clin Oncol. 2009; 27:6006-11.

15. Spigel DR, Waterhouse DM, Lane S, Legenne P, Bhatt K. Efficacy and safety of oral topotecan and bevacizumab combination as second-line treatment for relapsed smallcell lung cancer: an open-label multicenter single-arm phase II study. Clin Lung Cancer. 2013; 14:356-63.

16. Allen JW, Moon J, Redman M, Gadgeel SM, Kelly K, Mack PC, Saba HM, Mohamed MK, Jahanzeb M, Gandara DR. Southwest Oncology Group S0802: a randomized, phase II trial of weekly topotecan with and without ziv-aflibercept in patients with platinum-treated small-cell lung cancer. J Clin Oncol. 2014; 32:2463-70.

17. Spigel DR, Townley PM, Waterhouse DM, Fang L, Adiguzel I, Huang JE, Karlin DA, Faoro L, Scappaticci FA, Socinski MA. Randomized phase II study of bevacizumab in combination with chemotherapy in previously untreated extensive-stage small-cell lung cancer: results from the SALUTE trial. J Clin Oncol. 2011;29:2215-22.

18. Pujol JL, Lavole A, Quoix E, Molinier O, Souquet PJ, Barlesi F, Le Caer H, Moro-Sibilot D, Fournel P, Oster JP, Chatellain P, Barre P, Jeannin G, et al; French Cooperative Thoracic Intergroup (IFCT); French Cooperative Thoracic Intergroup IFCT. Randomized phase II-III study of bevacizumab in combination with chemotherapy in previously untreated extensive small-cell lung cancer: results from the IFCT-0802 trial†. Ann Oncol. 2015; 26:908-14.

19. Lu S, Li L, Luo Y, Zhang L, Wu G, Chen Z, Huang C, Guo S, Zhang Y, Song X, Yu Y, Zhou C, Li W, et al. A multicenter, open-label, randomized phase II controlled study of rh-endostatin (Endostar) in combination with chemotherapy in previously untreated extensive-stage small-cell lung cancer. J Thorac Oncol. 2015; 10:206-11.

20. Chen JH, Luo YZ, Zhou WW, Zhou H, Wang Wei. [Clinical observation of recombinant human endostatin combined with carboplatin and etoposide for advanced small-cell lung cancer]. Joumal of Clinical Medicine in Practice. 2013; 17:26-28. [Article in Chinese].

21. Dai XL, Dong AH, Sun DM. [The clinical analysis of small cell lung cancer treatment with recombinant human endostatin injection and cis-platinum complexes]. Chin J Med Prim Pharm. 2012; 19:1767-68. [Article in Chinese].

22. Li KY, Tang YL. [Observation of the Short-term Efficacy and Safety of Recombinant Human Endostatin and EP Treatment of Advanced Small-Cell Lung Cancer]. Yi Xue Xin Zhi Za Zhi. 2010; 20: 98-102. [Article in Chinese].

23. Wang ZJ. [Clinical Efficacy of Endostar Combined with EP Scheme for the Treatment of Small Cell Lung Cancer]. J Clin Res. 2011; 28:257-258. [Article in Chinese].

24. Hu HT, Gong CM, Zeng LJ, Zhang T. [Recombinant human endostatin combined with topotecan and cisplatin regimen 
for advanced small-cell lung cancer]. J Reg Anat Oper Surg. 2011; 20:190-191. [Article in Chinese].

25. Liu F, Yang ZY, Meng XL, Wang GH, Zhao EF, Shi FM. [Thalidomide Combined with EP Scheme for the Treatment of small-cell lung cancer]. Modern Oncology. 2011; 19:2462-63. [Article in Chinese].

26. Cheng F. [The clinical study of IP Scheme Combined with Thalidomide for the Treatment of Relapsed Small-cell Lung Cancer]. Mod Diagn Treat. 2015; 26:1292-93. [Article in Chinese].

27. Liu F, Yang ZY, Meng XL, Wang GH, Zhao EF, Shi FM. [Influence of Progression-Free Survival of Therapy with Cisplatin Plus Etposide with Thalidomide in Patients with Small Cell Lung Cancer]. Clinical Misdiagnosis \& Mistherapy. 2012; 25:41-43. [Article in Chinese].

28. Liu F, Meng XL, Wang GH, Shi FM, Zhao EF. [The clinical study of Thalidomide Combined with IP Scheme for the Second-Line Treatment of Small-cell Lung Cancer]. Modern Joumal of Integrated Traditional Chinese and Western Medicine. 2013; 22:277-78. [Article in Chinese].

29. Pujol JL, Breton JL, Gervais R, Tanguy ML, Quoix E, David P, Janicot H, Westeel V, Gameroff S, Genève J, Maraninchi D. Phase III double-blind, placebo-controlled study of thalidomide in extensive-disease small-cell lung cancer after response to chemotherapy: an intergroup study FNCLCC cleo04 IFCT 00-01. J Clin Oncol. 2007; 25:3945-51.

30. Lee SM, Woll PJ, Rudd R, Ferry D, O'Brien M, Middleton G, Spiro S, James L, Ali K, Jitlal M, Hackshaw A. Antiangiogenic therapy using thalidomide combined with chemotherapy in small cell lung cancer: a randomized, double-blind, placebo-controlled trial. J Natl Cancer Inst. 2009; 101:1049-57.

31. Arnold AM, Seymour L, Smylie M, Ding K, Ung Y, Findlay B, Lee CW, Djurfeldt M, Whitehead M, Ellis P, Goss G, Chan A, Meharchand J, et al; National Cancer Institute of Canada Clinical Trials Group Study BR.20. Phase II study of vandetanib or placebo in small-cell lung cancer patients after complete or partial response to induction chemotherapy with or without radiation therapy: National Cancer Institute of Canada Clinical Trials Group Study BR.20. J Clin Oncol. 2007; 25:4278-84.

32. Lauro S, Onesti CE, Righini R, Marchetti P. The use of bevacizumab in non-small cell lung cancer: an update. Anticancer Res. 2014; 34:1537-45. Review.

33. Pal SK, Figlin RA, Reckamp K. Targeted therapies for nonsmall cell lung cancer: an evolving landscape. Mol Cancer Ther. 2010; 9:1931-44.

34. Wedge SR, Ogilvie DJ, Dukes M, Kendrew J, Chester R, Jackson JA, Boffey SJ, Valentine PJ, Curwen JO, Musgrove HL, Graham GA, Hughes GD, Thomas AP, et al. ZD6474 inhibits vascular endothelial growth factor signaling, angiogenesis, and tumor growth following oral administration. Cancer Res. 2002; 62:4645-55.

35. Ciardiello F, Caputo R, Damiano V, Caputo R, Troiani T, Vitagliano D, Carlomagno F, Veneziani BM, Fontanini G, Bianco AR, Tortora G. Antitumor effects of ZD6474, a small molecule vascular endothelial growth factor receptor tyrosine kinase inhibitor, with additional activity against epidermal growth factor receptor tyrosine kinase. Clin Cancer Res. 2003; 9:1546-56.

36. Carlomagno F, Vitagliano D, Guida T, Ciardiello F, Tortora G, Vecchio G, Ryan AJ, Fontanini G, Fusco A, Santoro M. ZD6474, an orally available inhibitor of KDR tyrosine kinase activity, efficiently blocks oncogenic RET kinases. Cancer Res. 2002;62:7284-90.

37. Franks ME, Macpherson GR, Figg WD. Thalidomide. Lancet. 2004; 363:1802-11. Review.

38. Bergers G, Hanahan D. Modes of resistance to antiangiogenic therapy. Nat Rev Cancer. 2008; 8:592-603.

39. Blagosklonny MV. How Avastin potentiates chemotherapeutic drugs: action and reaction in antiangiogenic therapy. Cancer Biol Ther. 2005; 4:1307-10. Epub 2005 Dec 11. Review.

40. Sane DC, Anton L, Brosnihan KB. Angiogenic growth factors and hypertension. Angiogenesis. 2004; 7:193-201. Review.

41. Steeghs N, Gelderblom H, Roodt JO, Christensen O, Rajagopalan P, Hovens M, Putter H, Rabelink TJ, de Koning E. Hypertension and rarefaction during treatment with telatinib, a small molecule angiogenesis inhibitor. Clin Cancer Res. 2008; 14:3470-6.

42. Kamba T, McDonald DM. Mechanisms of adverse effects of anti-VEGF therapy for cancer. Br J Cancer. 2007; 96:178895. Epub 2007 May 22.

43. Moher D, Liberati A, Tetzlaff J, Altman DG; PRISMA Group. Preferred reporting items for systematic reviews and meta-analyses: the PRISMA statement. Int J Surg. 2010; 8:336-41.

44. Therasse P, Arbuck SG, Eisenhauer EA, Wanders J, Kaplan RS, Rubinstein L, Verweij J, Van Glabbeke M, van Oosterom AT, Christian MC, Gwyther SG. New guidelines to evaluate the response to treatment in solid tumors. European Organization for Research and Treatment of Cancer, National Cancer Institute of the United States, National Cancer Institute of Canada. J Natl Cancer Inst. 2000; 92:205-16.

45. World Health Organization. WHO Handbook for Reporting the Results of Cancer Treatment. Geneva, Switzerland, WHO Offset Publication No. 48, 1979.

46. National Cancer Institute. CTEP: NCI Guidance on CTC Terminology Applications. Bethesda, MD: National Cancer Institute; 2006. 
47. Mantel N, Haenszel W. Statistical aspects of the analysis of data from retrospective studies of disease. J Natl Cancer Inst 1959; 22: 719e48.

48. Tierney JF, Stewart LA, Ghersi D, Burdett S, Sydes MR. Practical methods for incorporating summary time-to-event data into meta-analysis. Trials. 2007; 8: 16.

49. Higgins JP, Thompson SG, Deeks JJ, Altman DG. Measuring inconsistency in meta-analyses. BMJ. 2003; 327: $557-60$.
50. Ford AC, Forman D, Hunt RH, Yuan Y and Moayyedi P. Helicobacter pylori eradication therapy to prevent gastric cancer in healthy asymptomatic infected individuals: systematic review and meta-analysis of randomized controlled trials. BMJ. 2014; 348: g3174. 